\title{
TINGKAT PARTISIPASI ANGGOTA KELOMPOK TANI DI KELURAHAN MALAKKE KECAMATAN BELAWA KABUPATEN WAJO
}

\section{Level of Participation of Farmer Group Members In Malakke, Belawa Sub-District, Wajo District}

\author{
Ab. Ellung, Yusriadi, A. Erna, dan Harsani \\ Prodi Pertanian Agribisnis, Fakultas Pertanian, Peternakan dan Perikanan \\ Universitas Muhammadiyah Parepare \\ e-mail: ellungbelawa@gmail.com
}

Received: 26 Januari 2021; Accepted: 7 Mei 2021; Published: 25 Juni 2021

\begin{abstract}
ABSTRAK
Penelitian yang dilakukan dengan tujuan untuk mengetahui tingkat partisipasi anggota kelompok tani yang ada terhadap kegiatan kelompok tani dan faktor yang mempengaruhi tingkat pasrtisipasi anggota kelompok tani yang dibentuk di kelurahan Malakke, Kecamatan Belawa Kabupaten Wajo. Jenis penelitian ini merupakan penelitian kuantitatif deskriptif yang merupakan jenis penelitian yang dapat menggambarkan suatu fenomena yang terjadi dalam masyarakat suatu wilayah. Alat analisa data digunakan adalah dengan menggunakan Skala Likert dan regresi linier berganda dengan skala pengukuran yang terbagi atas empat jawaban yaitu Selalu (4), Sering (3), Jarang (2), dan Tidak Pernah (1). Pengukuran variabel tingkat partisipasi anggota kelompok tani digunakan sub variabel partisipasi dalam perencanaan program kelompok tani, pertisipasi dalam pelaksanaan program kelompok tani, partisipasi dalam tahap evaluasi program kelompok tani, komunikasi yang intensif dan kesempatan berpartisipasi. Hasil penelitian yang dilakukan menunjukkan tingkat partisipasi anggota kelompok tani yang ada di kelurahan Malakke Kecamatan Belawa masih tergolong rendah atau kurang.
\end{abstract}

Kata kunci: Tingkat partisipasi, kelompok tani, partisipasi anggota

\begin{abstract}
Research conducted with the purpose of knowing the participation rate of farmers groups and factor affecting the participation rate of farmers' groups in Malakke in Wajo district. This type of research is a research that describes a phenomenon that occurs in the society of a region. Data analyzer tools used are by using multiple liner scales and regression with a measurement scale divided over four answers that are always (4), often (3), rarely (2) and inconveniently. The measurement of the participation rate of the peasant group members was used sub variable participation in the planning of the farm group program, participation in the implementation of the farm group program, participation in the evaluation stage of the farm group program, intensive communication, and participating opportunities. Research results showed that the participation rate of the members of the farm group in the kelurahan Malakke Kecamatan Belawa is still relatively low or less.
\end{abstract}

Keywords: Participation level, farmer group, members participation

Diterbitkan Oleh, 


\section{PENDAHULUAN}

Partisipasi merupakan bentuk keterlibatan atau peran dari masyarakat dengan ikut atau memberikan sumbangan kepada kelompok dalam usaha mencapai suatu tujuan baik itu berupa ide, bantuan fisik, finansial, maupun bantuan dalam bentuk lain yang dipengaruhi oleh adanya emosi atau perasaan di dalam situasi suatu kelompok. Keterlibatan aktif dalam berpartisipasi, tidak hanya dilihat dari keterlibatan jasmaniah saja, tetapi juga dapat diartikan sebagai keterlibatan pikiran, emosi, atau perasaan seseorang dalam situasi kelompok yang memjadi faktor pendorong untuk memberikan sumbangan kepada kelompok dalam usaha mecapai tujuan.

Kelompok tani terbentuk karena adanya kesamaan kepentingan diantara petani yang menjadi anggota kelompok tani tersebut kemampuan untuk melakukan pemanfaatan terhadap seluruh sumberdaya alam, manusia, modal, informasi, serta sarana dan prasarana dalam menjalankan usaha tani yang mereka miliki. Kelompok tani yang terbentuk menjadi tumpuan atau harapan untuk membantu peningkatan agar petani dapat lebih sejahtera dengan melihat peran atau partisipasi serta sumbangan mereka baik berupa ide maupun materi anggota kelompok tani dalam tahap perencanaan, pelaksanaan kegiatan usahatani maupun program pemerintah dalam dalam bidang pertanian. Salah satu contoh kelompok tani yang terbentuk ialah yang yang terdapat di Kelurahan Malakke, Kecamatan Belawa Kabupaten Wajo.

Kecamatan Belawa merupakan daerah yang masyarakatnya berprofesi sebagai petani sehingga kelompok tani yang terbentuk dapat memberikan pengaruh positif melalui peran anggotanya. Maka dari itu, Pengukuran tingkat partisipasi anggota kelompok tani dapat dilihat dengan Partisipasi dalam tahap perencanaan, pelaksanaan usahatani dan tahap evaluasi program kelompk tani yang dilaksanakan.

\section{METODE PENELITIAN}

\section{Tempat dan Waktu Penelitian}

Penelitian ini dilaksanakan di Kelurahan Malakke Kecamatan Belawa Kabupaten wajo,
Penelitian dilakukan selama 2 bulan yakni bulan Juni - Juli 2019.

\section{Penentuan Populasi dan Sampel}

Pengambilan sampel dalam penelitian ini menggunakan metode purposive sampling/ atau dengan kesengajaan dengan memilih satu kelompok tani. Jumlah populasi dalam penelitian ini 25 orang yang tergabung dalam satu kelompok tani

\section{Metode Analisis Data}

Penelitian ini akan disusun beberapa pertanyaan yang diberikan kepada 25 responden yang menjadi anggota kelompok tani dengan cara wawancara atau dengan menggunakan kuisioner. Jawaban dari kuisioner akan dihubungkan atau dinyatakan dengan menggunakan kategori kata kata sebagai berikut :
a. Selalu
$(\mathrm{SL})=4$
b. Sering
$(\mathrm{SR})=3$
c. Jarang
$(\mathrm{JR}) \quad=2$
d. Tidak Pernah
(TP) $=1$

\section{Indikator Penelitian} berikut:

Adapun indikator penelitian adalah sebagai

1. Partisipasi dalam tahap Perencanaan

Tahap perencanaan adalah menentukan halhal yang ingin dicapai di masa yang akan datang.

2. Partisipasi dalam tahap Pelaksanaan

Tahap pelaksanaan adalah tahap dimana halhal yang akan atau yang telah direncanakan untuk mencapai suatu tujuan mulai dilakukan.

3. Partisipasi dalam tahap Pengawasan

Sistem yang digunakan sebagi standar pelaksanaan kegiatan/program

Peringkat keaktifan partisipasi dilakuakan dengan cara perhitungan skor masing-masing pertanyaan.

Untuk menjawab rumusan masalah kedua digunakan alat analisis data yaitu dengan menggunakan regresi linier berganda untuk menguji faktor-faktor yang mempengaruhi partisipasi anggota kelompok tani.

Diterbitkan Oleh,

Unit Penelitian dan Pengabdian Masyarakat, Politeknik Pembangunan Pertanian Gowa

http://ejournal.polbangtan-gowa.ac.id 


\section{HASIL DAN PEMBAHASAN}

\section{Tingkat Partisipasi Anggota Kelompok Tani Di Kelurahan Malakke Kecamatan Belawa}

Nilai secara keseluruhan dari semua variabel yang ditentukan dengan menjumlahkan setiap total skor dari setiap skor keseluruhan variable maka, dapat ditentukan klasifikasi tingkat partisipasi anggota kelompok tani. Adapun tingkat partisipasi anggota kelompok tani yang ada di kelurahan Malakke, Kec.Belawa dapat dilihat pada tabel 1 .

Tabel 1. Hasil analisis data keseluruhan variabel tingkat partisipasi anggota kelompok tani (Massumpuloloe) di Kelurahan Malakke Kec. Belawa

\begin{tabular}{cccc}
\hline Variabel & Sub variable & Nilai & Keterangan \\
\hline & Tahap perencanaan program & 168 & Jarang \\
kelompok tani & & \\
$\begin{array}{c}\text { Tingkat Partisipsi } \\
\text { Anggota Kelopok } \\
\text { Tani }\end{array}$ & Tahap Pelaksanaan Program & 176 & Jarang \\
& Kelompok tani. & & Tidak Pernah \\
& Tahap Evaluasi Program & 123 & Sering \\
& Kelompok Tani & 190 & Jarang \\
& Komunikasi yang intensif & 161 & Jarang \\
\hline
\end{tabular}

Interpretasi Nilai

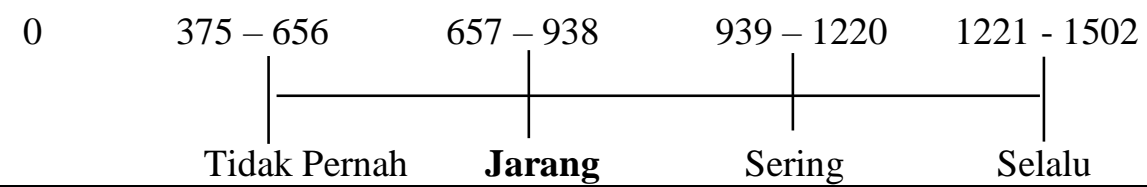

Hasil analisis data secara keseluruhan diperoleh dengan menjumlahkan total bobot nilai dari keseluruhan variabel. Adapun nilai keseluruhan dari ketiga variabel adalah 818 dan berada pada rentang atau interval nilai (657 - 938) dengan demikian dapat ditentukan bahwa tingkat partisipasi anggota kelompok tani Massumpuloloe di kelurahan Malakkke Kec. Belawa masuk dalam kategori Jarang. Dengan demikian dapat diartikan bahwa tingkat partisipasi anggota kelompok tani yang ada di kelurahan Malakke khususnya kelompok tani Massumpuloloe yang dijadikan sebagai kelompok yang mewakili kelompok lain yang ada masih rendah atau belum sesuai dengan apa yang diharapkan hal tersebut disebabkan oleh faktor kurangnya informasi yang didapat melalui kegiatan musyawarah yang tidak terjadwal dengan baik, kesibukan para anggota kelompok tani itu sendiri diluar masalah yang berkaitan dengan Diterbitkan Oleh, Unit Penelitian dan Pengabdian Masyarakat, Politeknik Pembangunan Pertanian Gowa http://ejournal.polbangtan-gowa.ac.id kelompok tani serta rendahnya pemahaman anggota kelompok tani akan pentingnya suatu kelompok tani untuk mendorong kemajuan usaha tani yang mereka lakukan. Sehingga diperlukan langkah bagaimana agar masyarakat dapat lebih mengerti akan perannya dalam memajukan pertanian maupun eksistensi kelompoknya dan apakah dengan adanya kelompok tani tersebut memang dapat memberikan dampak nyata bagi para petani yang berada di dalamya.

Hasil penelitian tingkat partisipasi anggota kelompok tani di kelurahan Malakke sejalan atau hampir serupa dengan penelitian yang dilakukan oleh peneliti terdahulu yang mengangkat variabel serupa seperti perencanaan, pelaksanaan dan evaluasi meskipun dengan hasil atau tingkat partisipasi yang berbeda. penelitian yang dilakukan Edwin Maleba (2015) dengan judul Partisipasi Anggota Dalam Pengembangan Kelompok Tani di 
Desa Soatobaru Kecamatan Galela Barat, yang menyatakan bahwa tingkat partisipasi anggota kelompok tani Melati Jaya tergolong kurang aktif pada lima aspek karena masih minimnya informasi serta kurangnya inisiatif dari anggota kelompok tani,kelima aspek tersebut adalah,1) Kehadiran dalam penyusunan program,2) Keaktifan memberi masukan atau pendapat dalam penyusunan program,3) keaktifan dalam pelaksanaan kegiatan kelompok,4) Keaktifan evaluasi program dalam kelompok dan ke 5) Keaktifan dalam memberi masukan atau pendapat dalam evaluasi.

\section{Faktor - faktor yang Mempengaruhi Partisipasi Anggota Kelompok Tani}

Koefisien regresi merupakan suatu alat ukur yang juga dapat digunakan untuk mengukur dan meramalkan perubahan nilai variabel terikat apabila terjadi perubahan nilai variabel bebas dalam hal ini variabel usia, tingkat pendidikan, tingkat pendapatan, komunikasi yang intensif dan kesempatan berpartisipasi terhadap variabel terikat yaitu tingkat partisipasi anggota kelompok tani, dapat dilihat pada tabel 2.

Tabel 2. Hasil koefisien regresi

\begin{tabular}{lccc}
\hline \multicolumn{1}{c}{ Variabel } & Koefisien Regresi & Signifikansi & Taraf Kesalahan \\
\hline Usia (X1) & -0.012 & 0.892 & \\
Pendapatan (X2) & $-1,122,000$ & 0.668 & \\
Pendidikan (X3) & 1,749 & 0.266 & $0,05(5 \%)$ \\
Komunikasi Intensif (X4) & 1,604 & 0.017 & \\
Kesempatan Berpartisipasi (X5) & 1,022 & 0.221 & \\
\hline
\end{tabular}

Tabel 2 menunjukkan jika usia (X1) bertambah maka diprediksi tingkat partisipasi anggota kelompok tani menurun sebesar -0.012, jika pendapatan, (X2) bertambah maka tingkat partisipasi anggota kelompok tani menurun sebesar $-1,122,000$, jika tingkat pendidikan (X3) meningkat maka tingkat partisipasi anggota kelompok tani meningkat sebesar 1,749. jika komunikasi yang intensif (X4) meningkat maka tingkat partisipasi anggota kelompok tani meningkat sebesar 1,604 dan jika kesempatan berpartisipasi (X5) meningkat maka tingkat partisipasi anggota kelompok tani meningkat sebesar 1,022.

Tabel diatas menunjukkan bahwa variabel usia (X1) dan pendapatan (X2) memiliki nilai koefisien regresi yang minus, hal tersebut mengindikasikan bahwa peningkatan usia dan pendapatan petani tidak akan berdampak positif pada peningkatan partisipasi anggota kelompok tani dengan nilai signifikansi diatas taraf kesalahan 5. Hasil tersebut sejalan dengan penelitian yang dilakukan oleh Isyaturriyadhah, Asnawati dan Effy Yudiawati (2017) yang berjudul Faktor-faktor yang Mempengaruhi Partisipasi Anggota Kelompok Gabungan Kelompok Tani Tanjung Sehati Dalam

Diterbitkan Oleh, Unit Penelitian dan Pengabdian Masyarakat, Politeknik Pembangunan Pertanian Gowa http://ejournal.polbangtan-gowa.ac.id
Kegiatan Kelompok Di Kabupaten Merangin yang menunjukkan hasil bahwa variabel usia tidak memberikan pengaruh yang nyata terhadap tingkat partisipasi gabungan anggota kelompok tani.

Kemudian untuk variabel pendidikan (X3) menunjukkan nilai koefisien regresi sebesar 1,749 yang mengindikasikan bahwa semakin tinggi tingkat pendidikan petani maka hal tersebut mampu meningkatkan partisipasi anggota kelompok tani. Hal tersebut terjadi karena dengan memiliki tingkat pendidikan yang tinggi maka petani merasa pantas untuk ikut berpartisipasi dalam proses perencanaan, pelaksanaan dan evaluasi program kelompok tani.

Hasil penelitian ini didukung oleh Muh. Sahwi, Rudianto dan Ulfa Rafi (2016) dalam hasil penelitian mengemukakan bahwa semakin tinggi pendidikan seseorang maka semakin kuat pula keinginannya untuk ikut dalam partisipasi penyusunan rencana program pengembangan desa. Hal tersebut terjadi karena adanya kepercayaan diri yang timbul dalam proses partisipasi jika memiliki tingkat pendidikan yang lebih tinggi.

Variabel selanjutnya yaitu komunikasi yang intensif (X4) menunjukkan nilai koefisien 
regresi sebesar 1,604 yang mengindikasikan bahwa semakin sering dilakukan komunikasi yang intensif antara para anggota kelompok tani maka hal tersebut mampu meningkatkan tingkat partisipasi anggota kelompok tani. Hal tersebut terjadi karena dengan dilakukannya komunikasi yang intensif antar para anggota kelompok tani maka pertukaran informasi semakin cepat terjadi sehingga para anggota kelompok tani memiliki refrensi informasi yang cukup untuk ikut dalam partisipasi perencanaan, pelaksanaan dan evaluasi. Hasil penelitian tersebut dipertegas dalam penelitian yang dilakukan oleh Zulkarnain dan Aswin Hamid (2014) yang mengemukakan temuan bahwa interaksi yang terjadi antara para kelompok tani menyebabkan bertambahnya jumlah anggota kelompok tani yang ikut dalam partisipasi penyusunan program pertanian. Interaksi yang terjadi tersebut termasuk didalamnya komunikasi antara para petani.

Kemudian untuk variabel kesempatan berpartisipasi (X5) menunjukkan nilai koefisien regresi sebesar 0,221 yang mengindikasikan bahwa semakin besar kesempatan berpartisipasi yang diberikan kepada petani maka dapat meningkatkan tingkat partisipasi anggota kelompok tani. Kesempatan berpartisipasi diwujudkan dengan memberikan ruang yang luas kepda seluruh anggota kelompok tani untuk turut aktif dan mengambil inisiatif yang didasari oleh pendapatn dan refrensi informasi masing-masing anggota.

Penelitian ini dikuatkan dengan hasil penelitian dalam jurnal Agro Ekonomi oleh Rochmat Subagja (2016) yang menyatakan bahwa tingkat partisipasi anggota kelompok tani dalam penyusunan program desa dalam ditingkatkan dengan pemberian kesempatan yang terbuka secara luas kepada seluruh anggota kelompok tani. Pemberian kesempatan dapat dilakukan melakukan sosialisasi dan undangan secara terbuka kepada seluruh anggota kelompok tani dan gabungan kelompok tani.

\section{KESIMPULAN DAN SARAN}

\section{Kesimpulan}

1. Berdasarkan hasil penelitian yang dilakukan dapat ditarik kesimpulan bahwa tingkat partisipasi anggota kelompok tani di kelurahan

Diterbitkan Oleh,

Unit Penelitian dan Pengabdian Masyarakat, Politeknik Pembangunan Pertanian Gowa

http://ejournal.polbangtan-gowa.ac.id
Malakke,Kecamatan Belawa masih tergolong rendah.

2. Variabel yang paling berpengaruh positif terhadap tingkat partisipasi anggota kelompok tani yaitu Pendidikan ( x3 ), Komunikasi yang intensif ( $\mathrm{x} 4$ ) dan Kesempatan berpartisipasi ( x5 )

\section{Saran}

1. Sebaiknya Kelompok tani yang ada dibuatkan struktur yang jelas guna mempermudah dalam menentukan dan mengembangkan kelompok serta dilakukan pendataan terhadap kelompok tani yang memang terus aktif dengan kelompok tani yang tidak berfungsi.

2. Sebaiknya lebih dilakukan pendekatan kepada masyarakat guna menumbuhkan kesadaran akan fungsi dan perlunya kelompok tani agar termotivasi untuk berperan di dalamnya.

3. Saran untuk peneliti agar dalam pengambilan data dan pengolahan data dilakukan dengan efisien dan tidak menunda-nunda agar cepat selesai dan dapat melengkapi data yang diperlukan dengan waktu yang tersedia.

\section{DAFTAR PUSTAKA}

Badra.V.M.2011. Partisipasi Petani Sawah dalam Program Bantuan Langsung Pupuk(BLP) di Desa Negara Ratu Kecamatan Natar Kabupaten Langsung Selatan.skripsi. Universitas Lampung.Bandar Langsung.

Dien. Y. 2012, Partisipasi Masyarakat Terhadap Program Nasional Pemberdayaan Masyarakat Mandiri Perdesaan Didesa Kauditan II Kecamatan Kauditan Kabupaten Minahasa Utara, Fakultas Pertanian Unsrat Manado.

Edwin Maleba,Venje V.Rantung,Welson M. Wangke,Yolanda P.I Rori. (2015). Partisipasi Anggota Dalam Pengembangan Kelompok Tani Di Desa Soatobaru Kecamatan Galela Barat.

Fahrudin,Adi,Ph.D. 2011. Pemberdayaan, Partisipasi, dan penguatan Kapasitas masyarakat. Bandung: Humaniora.

Gibson, L Janes, John M Ivancevich dan James H Donelly. 2003. Organization, Behavior, Structure and Process. 10 ${ }^{\text {th }}$ Edition. 
DOI: 10.52625/j-agr-sosekpenyuluhan.v17i1.181

Irwin.Chicago.

Istaruyyidah, Asnawati Is,Effy Yudiawaty. 2017.

Faktor-Faktor Yang Mempengaruhi

Partisipasi Anggota Gabungan Kelompok

Tani Tanjung Sehati Dalam Kegiatan

Kelompok Tani di Kabupaten

Meringin.Fakultas Pertanian Universitas Muara Bungo,Jambi.

Lokita, D. A. (2011). Partisipasi Masyarakat dalam Pengelolaan Sampah ( Kasus Implementasi Corporate Social Responsibility PT.Indocement Tunggal Prakarsa Tbk.di Desa Gunung Sari, Kecamatan Citeureup,Kabupaten Bogor).Institut Pertanian Bogor.

Manein Melgi Yuni,Juliana R.Mandei,Paulus A.P angemanan.(2016). Pasrtisipasi Anggota Kelompok Tani Dalam Pengelolaan Usahatani di Desa Matani,Kecamatan Tumpaan

Mardikanto, T, \& Soebianto, P. (2013). Pemberdayaan Masyarakat dalam Perspektif Kebijakan Publik (2nd.ed) Bandung: Alfabeta.

Monomimbar. M H. 2010. Partisipasi Anggota Kelompok Tani dalam Kegiatan Sekolah Lapangan Pengelolaan Tanaman Terpadu (SL-PTT)Jjagung.Fakultas Pertanian,Unsrat Manado.

Nasdian, Fredian Tonny. 2006. Pengembangan Masyarakat (community Development). Bogor.Institut Pertanian Bogor.

Shalihah Asma`Maratush.2018. fakor-Faktor Yang
Memengaruhi Partisipasi Petani Dalam Program Asuransi Usaha Tani Padi (AUTP) di Kecamatan Jonggol,Kabupaten Bogor. Fakultas Ekonomi dan Manajemen Institut Pertanian Bogor.

Slamet, M. (2003). Membentuk Pola Perilaku Manusia Pembangunan. Bogor: IPB Press.

Sumarto, Hetifah Sj.2009.Inovasi, Partisipasi, dan Good Governance: 20 Prakarsa inovatif dan Partisipatif di Indonesia. Jakarta : Yayasan Obor Indonesia.

Suyadi. 2009. Tropical Deforestation in Bukit Barisan Selatan National Park, Sumatera, Indonesia. Bogor Agricultural University. Bogor

Turagan Richo Richardo, Theodora M. Katindagho, Benu Olfie L.S. (2016). Partisipasi Anggota Pada Kelompok Tani Kalelon di Desa Kauneran,Kecamatan Sonder,Kabupaten Minahasa.

Winardi. 2004.Motivasi dan Pemotivasi dalam Manajemen.PT.Raja Grafindo.Jakarta

Yani Diarsi Eka,Pepi Rosina Pertiwi,Argatta Sigit.(2013). Partisipasi Anggota Kelompok Tani Dalam Menganalisis Data Keadaan Pada Usahatani Sayuran. Program Studi Agribisnis, Jurusan Biologi FMIPA-UT.

Yuliaty. M. 2005, Partisipasi Masyarakat Dalam Memelihara Benda Cagar Budaya Di Pulau Penyengat Sebagai Upaya Pelestarian Warisan Budaya Melayu, Tesis, Universitas Diponegoro Semarang.

Diterbitkan Oleh, 